\title{
The use of BLT humanized mice to investigate the immune reconstitution of the gastrointestinal tract
}

\author{
Angela Wahl and J. Victor Garcia \\ Division of Infectious Diseases, UNC Center for AIDS Research, University of North Carolina \\ School of Medicine, Genetic Medicine Building, Chapel Hill, NC 27599-7042, Tel: 919-843-9600, \\ Fax: 919-966-6870
}

\begin{abstract}
The gastrointestinal (GI) track represents an important battlefield where pathogens first try to gain entry into a host. It is also a universe where highly diverse and ever changing inhabitants co-exist in an exceptional equilibrium without parallel in any other organ system of the body. The gut as an organ has its own well-developed and fully functional immune organization that is similar and yet different in many important ways to the rest of the immune system. Both a compromised and an overactive immune system in the gut can have dire and severe consequences to human health. It has therefore been of great interest to develop animal models that recapitulate key aspects of the human condition to better understand the interplay of the host immune system with its friends and its foes. However, reconstitution of the GI tract in humanized mice has been difficult and highly variable in different systems. A better molecular understanding of the development of the gut immune system in mice has provided critical cues that have been recently used to develop novel humanized mouse models that fully recapitulate the genesis and key functions of the gut immune system of humans. Of particular interest is the presence of human gut-associated lymphoid tissue (GALT) aggregates in the gut of NOD/SCID BLT humanized mice that demonstrate the faithful development of bona fide human plasma cells capable of migrating to the lamina propria and producing human $\operatorname{Ig} \mathrm{A} 1$ and $\operatorname{Ig} \mathrm{A} 2$.
\end{abstract}

\author{
Keywords \\ humanized mice; BLT; GALT; NOD/SCID; NSG; NOG
}

\section{The Gl: a critical immune organ}

The immune system's function is to respond to pathogens. In the gut however, the immune system has to respond to pathogens while remaining somewhat unresponsive to the commensal flora and a large range of food antigens (Macdonald and Monteleone, 2005).

\footnotetext{
(C) 2014 Elsevier B.V. All rights reserved.

Corresponding authors: Wahl, A. (angela_wahl@med.unc.edu) and Garcia, J.V. (victor_garcia@med.unc.edu).
}

Publisher's Disclaimer: This is a PDF file of an unedited manuscript that has been accepted for publication. As a service to our customers we are providing this early version of the manuscript. The manuscript will undergo copyediting, typesetting, and review of the resulting proof before it is published in its final citable form. Please note that during the production process errors may be discovered which could affect the content, and all legal disclaimers that apply to the journal pertain. 
Abnormalities in gut immune function have been implicated in the development of ulcerative colitis and Crohn's disease (Chandran et al., 2003). One specific instance in which the need for a better understanding human GALT genesis and regeneration has been made extremely clear is illustrated during the course of HIV infection. Even at the earliest stages of infection, the virus inflicts extraordinary damage to the gut immune system that is incomparable to the changes observed in the rest of the body and certainly not reflected in peripheral blood (Dandekar, 2007; Mehandru and Dandekar, 2008). This damage is widespread and long lasting. Even extensive antiretroviral therapy cannot appreciably restore the harm done (Guadalupe et al., 2003).

\section{Human gut development}

Due to the intrinsic difficulties in performing studies in humans, little is known about human GALT development. However, this is not the case in other species. Recent studies have generated a great deal of relevant and significant insight into the molecular and cellular mechanisms by which GALT genesis occurs in mice (Mebius, 2003; Kiyono and Fukuyama, 2004; van de Pavert and Mebius, 2010). Though a series of elegant genetic experiments, cryptopatches have been identified as the key site for the organogenesis of isolated lymphoid tissue in the gut (Kanamori et al., 1996; Saito et al., 1998; Oida et al., 2000; Suzuki et al., 2000; Eberl and Littman, 2004; Eberl, 2005; Pabst et al., 2005; Bouskra et al., 2008). To date, the presence of these anlagen for immune aggregates in humans has not been fully established. Despite these advances in our knowledge of mouse GALT development, our understanding of human GALT genesis is sparse. The difficulties associated with performing similar developmental studies in humans has limited our current knowledge of human GALT to anatomical and pathological descriptions (Cornes, 1965). In humans, lymphocyte migration into mucosal tissues like the gut is the result of a series of poorly understood but highly complex interactions involving cell adhesion molecules and chemokines with their corresponding receptors (Kunkel and Butcher, 2002). In a recent series of studies, our laboratory focused on the evaluation of gut reconstitution in several different humanized mouse models. The results demonstrated a seminal role for cryptopatches in human GALT genesis.

\section{Humanized mouse models}

Early in the 1980's, pioneering work from the laboratory of John E. Dick and others established the repopulation of immunodeficient mice with human hematopoietic cells (Kamel-Reid and Dick, 1988; Dick, 1991; Dick et al., 1991; Vormoor et al., 1994; Hogan et al., 1997; Wang et al., 1998). Since then many variants of "humanized mice" have been described and these models have been reviewed extensively elsewhere (Denton and Garcia, 2009; Brehm et al., 2010; Denton and Garcia, 2011; Shultz et al., 2012). It was only after much iteration, that finally one humanized mouse model was developed with remarkable reconstitution of the GI: the bone marrow/liver/thymus or BLT humanized mouse (Melkus et al., 2006; Sun et al., 2007).

Virtually all modern humanized mouse models are produced via transplantation of human hematopoietic cells into one of several different strains of immune deficient mice. This 
results in systemic reconstitution with human hematopoietic cells including B cells, monocytes/macrophages and $\mathrm{T}$ cells. In most models, the human $\mathrm{T}$ cells are produced in the mouse thymus and are presumed to be educated in the context of mouse MHC I and II (Traggiai et al., 2004; Ishikawa et al., 2005; Shultz et al., 2005). In the case of BLT mice, human liver and thymus tissue are implanted under the kidney capsule to develop a functional human thymus in which $\mathrm{T}$ cells can develop in the presence of human thymic epithelium resulting in HLA I and II restriction (Wege et al., 2008; Olesen et al., 2011). The second step is a bone marrow transplant from which $\mathrm{T}$ cell progenitors and other human hematopoietic cells are derived resulting in systemic reconstitution with all types of human hematopoietic cells (Lan et al., 2006; Melkus et al., 2006).

\section{Early descriptions of gut reconstitution in humanized mice}

The first clear demonstration of the presence of human cells in the gut of humanized mice was made by Melkus et al (Melkus et al., 2006). In this manuscript, the presence of human cells in the GI of BLT mice was determined with immunohistochemistry. Human T cells, B cells and myeloid cells present in the GI tract of these mice were described as forming aggregates resembling gut-associated lymphoid tissue (Melkus et al., 2006). Subsequently, Sun et al. (Sun et al., 2007) performed a detail flow cytometric characterization of the different types of human T cells present in the GI tract of BLT mice. In this report, the investigators show the presence of human $\mathrm{T}$ and $\mathrm{B}$ cells, monocyte/macrophages and dendritic cells in all sections of the gut. In addition, they demonstrated substantial numbers of lamina propria (LP) and intraepithelial (IE) CD4+, CD8+ and CD4+CD8+ T cells in the small and large intestines (Sun et al., 2007). The presence of double positive $\mathrm{T}$ cells is characteristic of this human tissue (Carton et al., 2004) and is an indicator of its faithful reconstitution in BLT mice. Also of note is the fact that the human intestinal T cells present in BLT mice display a memory phenotype as is observed in the human gut (Sun et al., 2007). Another indication that the reconstitution of the gut in BLT mice is indeed reflective of the human gut is the presence of CD8 single positive T cells in the lamina propria that expressed both the CD8 $a$ and $C D 8 \beta$ chains which is in contrast with the exclusive expression of the CD8a chain in the double positive $\mathrm{T}$ cells also found in the lamina propria (Sun et al., 2007). All of these observations are fully consistent with what has been described for human gut (Abuzakouk et al., 1998; Carton et al., 2004).

Concurrent with the demonstration of the presence of human cells in the gut of BLT mice, Akkina and colleagues in an elegant study also demonstrated the presence of human lymphoid cells in the gut of humanized DKO mice using immunohistochemistry (Berges et al., 2008). The presence of human cells in the GI tract of these mice was subsequently confirmed by Hofer et al (Hofer et al., 2008). Similarly, the presence of human T cells in the gut of humanized NSG mice has also been described (Holt et al., 2010).

A recent study by Denton et al. investigated the differences and similarities in gut reconstitution between all of these humanized mouse models (Denton et al., 2012). This study presents a detailed head-to-head comparison between humanized DKO, NSG, NOD/ SCID BLT and NSG BLT mice. Since each of these strains of mice differs in the number of CD34+ cells needed for optimal engraftment, the investigators adjusted the number of cells 
used for transplantation to obtain optimal systemic reconstitution of each model. The authors noted that regardless of the mouse strain or the humanization protocol (i.e. transplantation alone or transplantation of thy/liv implanted animals) all mice were reconstituted as evidenced by the presence of human T cells in peripheral blood (Denton et al., 2012).

Analysis of the systemic reconstitution of each of these mouse models demonstrated the presence of human T cells in bone marrow, spleen, liver and lung. Extensive comparisons within and between models were conducted of which only a few showed differences between groups. The notable differences indicated somewhat lower levels of human cells in the tissues of humanized DKO mice. These results were evidence of the systemic reconstitution of each of these mouse models allowing as indicated below for a direct comparison of their gut reconstitution with $\mathrm{T}$ cells.

\section{A tale of two thymi}

In CD34+ cell transplant only mice made using DKO or NSG animals, all of the human T cells present are produced in the endogenous mouse thymus (Traggiai et al., 2004; Ishikawa et al., 2005; Shultz et al., 2005). In CD34+ cell transplanted NOD/SCID mice there are no human T cells (Palucka et al., 2003; Islas-Ohlmayer et al., 2004; Cravens et al., 2005). Therefore, in NOD/SCID BLT mice the only cells present are derived from the human thymic implant (Melkus et al., 2006). However, in NSG BLT mice, human T cells are produced in both the endogenous mouse thymus and the exogenous implanted human thymus (Denton et al., 2012). Regardless of the way in which mice are humanized or the strain used, in all cases, a diverse $\mathrm{T}$ cell receptor repertoire is generated indicating efficient T cell genesis and development (Traggiai et al., 2004; Melkus et al., 2006; Marodon et al., 2009). In NSG BLT mice, the vast majority of thymocytes originate from the implanted human tissue. The numbers of total thymocytes in NOD/SCID and NSG BLT mice are similar. However, the numbers of thymocytes in CD34+ cell transplanted only NSG or DKO mice were found to be significantly lower when compared to NSG and NOD/SCID BLT mice (Denton et al., 2012).

\section{Reconstitution of the GI tract with human T cells in different humanized mouse models}

Having established systemic reconstitution with human T cells in each of the different humanized mouse models, an analysis for the presence of $\mathrm{T}$ cells in the GI tract was performed (Denton et al., 2012). Both the large and small intestines were analyzed. Interestingly, whereas both of the BLT mouse models and the NSG CD34+ cell transplanted mice had significant levels of human $\mathrm{T}$ cells in all parts of the gut, these cells were present in lower levels in the tissues obtained from DKO CD34+ cell transplanted mice. In virtually all cases, this difference was statistically significant. Analysis for the presence of lamina propria and intraepithelial lymphocytes demonstrated the presence of these cells in both BLT models and CD34+ transplant only NSG mice, albeit in appreciably different amounts. However, these cells were virtually absent from DKO CD34+ cell transplanted mice (Denton et al., 2012). In all cases, BLT mice had the highest and most consistent levels of human T cells throughout all portions of the intestines. Both NOD/SCID and NSG BLT 
mice had similar levels of human $\mathrm{T}$ cells in the small intestine lamina propria. This was not the case in other portions of the intestines. Specifically, NOD/SCID BLT mice had more human intraepithelial lymphocytes in both the large and small intestine and in the large intestine lamina propria than NSG-BLT mice. NOD/SCID BLT mice had more human T cells in all portions of the intestine than CD34+ NSG transplanted mice. However, in the large intestine, CD34+ cell transplanted only NSG mice had more human intraepithelial and lamina propria lymphocytes than NSG-BLT mice.

\section{Qualitative differences between the human T cells present in humanized mice made using the NSG or NOD/SCID mouse strains}

The quantitative differences in the repopulation of the different parts of the gut between different models prompted the evaluation of other possible qualitative differences. Diversity in T cell receptor (TCR) expression is essential for a well functioning immune system. Analysis of the TCR repertoire in the T cells present in BLT mice generated in NOD/SCID and NSG strains has been recently reported (Denton et al., 2012). Small intestine intraepithelial and lamina propria lymphocytes were isolated from multiple mice and pooled for immunoscope analysis of TCR diversity. The results demonstrated that the TCR repertoire in the gut of these mice was quite diverse and included all of the 28 variable beta regions tested. Interestingly, the authors indicate that the diversity observed was reminiscent to that observed in young humans (Probert et al., 2007; Denton et al., 2012). One interesting observation reported was the fact that whereas the double positive $\mathrm{T}$ cells found in the small intestine of NOD/SCID BLT mice expressed the CD8aa homodimer, the T cells found in the small intestine of NSG BLT mice did not. This remarkable difference was taken as an indication that perhaps the mouse gamma chain molecule that is present in NOD/SCID BLT mice and but completely absent in the NSG BLT mice might contribute to the bona fide reconstitution of the NOD/SCID BLT mouse gut.

\section{The role of the gamma chain molecule and cryptopatches in the development of GALT in humanized mice}

The role of cryptopatches in the development of GALT in mice has been extensively documented (van de Pavert and Mebius, 2010). However, these important structures have been the subject of significant debate since they were originally considered to be absent in humans (Moghaddami et al., 1998; Pabst et al., 2005). The interest in the presence of these structures in humans has been fuelled by a recent report revealing the presence of structures resembling crytopatches in human gastrointestinal tissue (Lugering et al., 2010). This issue was recently addressed in great detail in a manuscript by Nochi et al (Nochi et al., 2013). In this report, the authors analyzed the presence of cryptopatches in two different strains of immunodeficient mice commonly used to generate humanized mice NOD/SCID and NSG. The critical difference between these two strains of mice that permitted this analysis was the presence or absence of the common gamma chain receptor molecule in NOD/SCID and NSG mice, respectively. 
The GALT consists of two major components: Peyer's patches and isolated lymphoid follicles. It is in these two distinct structures where antigen-primed $\mathrm{T}$ and B cells can be activated endowing them with the ability to migrate into the lamina propria where they can execute their functions. Peyer's patches are generated during gestation and their number increases until puberty (Cornes, 1965). In contrast, isolated lymphoid follicles develop after birth in response to commensal bacteria present in the gut (van de Pavert and Mebius, 2010). It is for these reasons that humanized mice can potentially develop lymphoid follicles but not Peyer's patches. The formation of isolated lymphoid follicles is elegantly orchestrated by a series of well-defined events that are dependent on the presence of lymphoid tissue inducer cells. Key to the development of isolated lymphoid follicles is the production of IL-7 by epithelial cells. IL-7 is necessary for the induction of lymphotoxin. Lymphotoxin in turn is responsible for the production of cytokines, chemokines and adhesion molecules by lymphoid tissue organizer cells. These molecules are essential for the recruitment and retention of lymphocytes (Eberl, 2005; Eberl, 2007). Therefore, IL-7R signaling is essential for GALT development.

IL-7R signaling is mediated by the common gamma chain of the IL-2 receptor gene. The common gamma chain is a cytokine receptor subunit that is shared by the IL-2, -4, -7, -9, -15 and -21 receptors (Wang et al., 2005). In the absence of this molecule, cells are unable to respond to the signaling initiated by the binding of these cytokines. Consistent with the lack of IL-7R signaling, cryptopatches only developed within the intestinal crypts of NOD/SCID mice and were not found anywhere within the gut of NSG mice (Nochi et al., 2013). Whereas in NOD/SCID mice these structures failed to fully develop due to the absence of mouse $\mathrm{T}$ and $\mathrm{B}$ cells, they did become enlarged with a follicle-associated epithelium.

Using flow cytometric analysis, at least two kinds of murine innate immune cells (IL-7Rapha+c-kit+) were identified in the intestines of NOD/SCID mice. One cell type expressed mouse CD4 which defined them as lymphoid tissue inducer cells. The second cell type expressed mouse NKp46 defining them as natural cytotoxicity-triggering receptor cells. It should be noted that these cells were absent in the gut of NSG mice. These results in total demonstrated the presence of cryptopatches in NOD/SCID mice that could serve as the basis for the development of GALT in these animals.

\section{Development of GALT-like structures in NOD/SCID BLT mice}

Examination of the GI tract of NOD/SCID BLT mice revealed the presence of immune aggregates in both the small and large intestine. Early after stem cell transplantation with human CD34+ cells, these aggregates contain mainly mouse CD45+ cells and a few human CD45+ cells (Nochi et al., 2013). Over time, these aggregates expand due to the accumulation of human T cells, B cells, monocyte/macrophages and dendritic cells. On the basis of the presence of all these different types of immune cells in these aggregates, they were defined as GALT-like structures (Jung et al., 2010). It is important to highlight that these structures were completely absent in all of the NSG mice examined in this report, providing a striking correlation between the presence of a common gamma chain and the presence of GALT in BLT humanized mice (Nochi et al., 2013). However, despite the absence of GALT structures in NSG BLT mice, their GI tract is well reconstituted with T 
cells, monocyte/macrophages and dendritic cells. Nevertheless, human B cells are almost completely absent in the gut of NSG BLT mice.

Human CD19+ B cells were mostly absent from the lamina propria of NOD/SCID BLT mice. B cells in NOD/SCID mice were almost exclusively found in the GALT and expressed activation-induced cytidine deaminase (Delker et al., 2009). Unswitched human IgM+ B cells together with class-switched human IgA+ and IgG+ cells were found in GALT structures of NOD/SCID BLT mice, reflective of heterogeneous populations of B cells in the process of differentiation into plasma cells. However, co-expression of human IgA with other markers like CD27, CD38 and CD138 together with a lack of HLA-DR expression confirmed the presence of fully differentiated plasma cells. Consistent with the sequential maturation and subsequent migration of plasma cells, significantly higher numbers of human $\operatorname{IgA}+$ cells than IgG or IgM cells were found in the lamina propria of NOD/SCID BLT mice. These cells were rarely found in NSG BLT mice suggesting that the existence of human plasma cells in the intestinal lamina propria of BLT mice is dependent on the presence of GALT structures. Of note, like in humans, both human IgA1 and IgA2 expressing cells were found in the gut of NOD/SCID BLT mice.

\section{The humanized BLT mouse as a model to study the role of the gut in HIV pathogenesis, transmission and prevention}

The gut is a tissue of great importance during the course of HIV disease. The gut houses the majority of the body's HIV target cells (Mowat and Viney, 1997). In developed nations, HIV is commonly acquired through the gut. Long after the initial infection HIV persists in the gut from where it can be transmitted to others (Shacklett and Anton, 2010). There are numerous clinical manifestations of gut involvement during HIV infection including diarrhea, dehydration and enteropathy. HIV infection also inflicts significant long-lasting damage to the immune system that is manifested by a systemic loss of peripheral and tissue CD4+ T cells. Damage to the immune system is mostly repaired after administration of antiretroviral therapy (ART) (Connick et al., 2000; Hirsch et al., 2004). Unfortunately, this most significant benefit of ART does not extend to the gut (Mehandru et al., 2006; Dandekar, 2007).

Because of the multiple roles that the gut plays in HIV disease there has been strong interest in the development and implementation of animal models that can recapitulate key aspects of HIV infection and pathogenesis in the gut. In this regard, humanized BLT mice have often served as outstanding models of HIV infection in the gut. Because of the extensive reconstitution of the gut of BLT mice they have also been extensively used to study rectal HIV transmission, its pathogenic sequela and its possible prevention (Sun et al., 2007; Chateau et al., 2013; Nochi et al., 2013). Humanized BLT mice were the first model ever used to study rectal HIV transmission. In a landmark paper, Sun et al. demonstrated that BLT mice could be infected after a single rectal exposure to HIV (Sun et al., 2007). The authors also demonstrated that infection resulted in significant destruction of the human $\mathrm{T}$ cells present throughout the entire gut of these animals. More recently, BLT mice were used to investigate the use of topical microbicides to prevent rectal HIV transmission (Chateau et al., 2013). In this study, humanized BLT mice were used to determine whether or not a 
single topical application of Tenofovir could prevent rectal HIV acquisition in BLT mice. The results from this study demonstrated that rectally applied Tenofovir is highly effective at preventing rectal HIV transmission and further validated the model for the study of HIV transmission and prevention approaches. More recently, Nochi et al demonstrated that the GALT structures themselves in BLT mice are targets for destruction by HIV as well as sites of extensive replication. All of these studies have taken advantage of the unique characteristics that set apart the BLT model for studies of the gut during health and disease.

\section{Summary}

The GALT is an essential component of a fully functional human immune system. Detail analyses of the GI tract of several commonly used humanized mouse models have been conducted. Whereas most models contain human lymphoid cells in their gut, only NOD/ SCID BLT mice contain aggregates resembling bona fide GALT structures and have human IgA-1 and - 2 expressing plasma cells in their intestines. The presence of these well-defined immune structures is dependent on the presence of cryptopatches. The presence of cryptopatches in turn is dependent on the expression of the common gamma chain of the IL-2 receptor. These observations have significant implications for the field of humanized mice since the vast majority of models currently in use take advantage of the higher levels of humanization that can be obtained in strains of mice lacking this gene such as NSG, NOG and DKO mice. Consequently, none of the humanized mice developed in these mouse strains develops human GALT structures or has human IgA producing plasma cells in their lamina propria. Therefore, currently, the NOD/SCID BLT humanized mouse model is the only available platform for the study of the development and function of human GALT during health and disease conditions.

\section{Acknowledgments}

This work was supported in part by grants AI33331, AI73146, AI82637 AI96138 and AI96113 from the National Institutes of Health. AW was supported in part by a Mathilde Krim Fellowship in Basic Biomedical Research (108684-55-RKMT) from the American Foundation for AIDS Research. The original research work on this area in our laboratory was also supported by the UNC Center for AIDS Research (AI50140), by the Japan Society for the Promotion of Science Research Fellowship and by the Young Researcher Overseas Visits Program for Vitalizing Brain Circulation. I also thank Dr. Hiroshi Kiyono for his kind support of this work and Morgan Chateau for her critical reading of this manuscript.

\section{References}

Abuzakouk M, Carton J, Feighery C, O'Donoghue DP, Weir DG, O'Farrelly C. CD4+ CD8+ and CD8alpha+ beta- T lymphocytes in human small intestinal lamina propria. Eur J Gastroenterol Hepatol. 1998; 10:325-9. [PubMed: 9855049]

Berges BK, Akkina SR, Folkvord JM, Connick E, Akkina R. Mucosal transmission of R5 and X4 tropic HIV-1 via vaginal and rectal routes in humanized Rag2-/- gammac -/- (RAG-hu) mice. Virology. 2008; 373:342-51. [PubMed: 18207484]

Bouskra D, Brezillon C, Berard M, Werts C, Varona R, Boneca IG, Eberl G. Lymphoid tissue genesis induced by commensals through NOD1 regulates intestinal homeostasis. Nature. 2008; 456:507-10. [PubMed: 18987631]

Brehm MA, Shultz LD, Greiner DL. Humanized mouse models to study human diseases. Curr Opin Endocrinol Diabetes Obes. 2010; 17:120-5. [PubMed: 20150806]

Carton J, Byrne B, Madrigal-Estebas L, O'Donoghue DP, O'Farrelly C. CD4+CD8+ human small intestinal $\mathrm{T}$ cells are decreased in coeliac patients, with CD8 expression downregulated on intra- 
epithelial T cells in the active disease. Eur J Gastroenterol Hepatol. 2004; 16:961-8. [PubMed: 15371918]

Chandran P, Satthaporn S, Robins A, Eremin O. Inflammatory bowel disease: dysfunction of GALT and gut bacterial flora (I). Surgeon. 2003; 1:63-75. [PubMed: 15573623]

Chateau ML, Denton PW, Swanson MD, McGowan I, Garcia JV. Rectal transmission of transmitted/ founder HIV-1 is efficiently prevented by topical $1 \%$ tenofovir in BLT humanized mice. PLoS ONE. 2013; 8:e60024. [PubMed: 23527295]

Connick E, Lederman MM, Kotzin BL, Spritzler J, Kuritzkes DR, St Clair M, Sevin AD, Fox L, Chiozzi MH, Leonard JM, Rousseau F, D’Arc Roe J, Martinez A, Kessler H, Landay A. Immune reconstitution in the first year of potent antiretroviral therapy and its relationship to virologic response. J Infect Dis. 2000; 181:358-63. [PubMed: 10608789]

Cornes JS. Number, size, and distribution of Peyer's patches in the human small intestine: Part I The development of Peyer's patches. Gut. 1965; 6:225-9. [PubMed: 18668776]

Cravens PD, Melkus MW, Padgett-Thomas A, Islas-Ohlmayer M, del P, Martin M, Garcia JV. Development and activation of human dendritic cells in vivo in a xenograft model of human hematopoiesis. Stem Cells. 2005; 23:264-78. [PubMed: 15671149]

Dandekar S. Pathogenesis of HIV in the gastrointestinal tract. Curr HIV/AIDS Rep. 2007; 4:10-5. [PubMed: 17338855]

Delker RK, Fugmann SD, Papavasiliou FN. A coming-of-age story: activation-induced cytidine deaminase turns 10. Nat Immunol. 2009; 10:1147-53. [PubMed: 19841648]

Denton PW, Garcia JV. Novel humanized murine models for HIV research. Curr HIV/AIDS Rep. 2009; 6:13-9. [PubMed: 19149992]

Denton PW, Garcia JV. Humanized Mouse Models of HIV Infection. AIDS Rev. 2011; 13:135-48. [PubMed: 21799532]

Denton PW, Nochi T, Lim A, Krisko JF, Martinez-Torres F, Choudhary SK, Wahl A, Olesen R, Zou W, Di Santo JP, Margolis DM, Garcia JV. IL-2 receptor gamma-chain molecule is critical for intestinal T-cell reconstitution in humanized mice. Mucosal Immunol. 2012; 5:555-66. [PubMed: 22569301]

Dick JE. Immune-deficient mice as models of normal and leukemic human hematopoiesis. Cancer cells. 1991; 3:39-48. [PubMed: 1851428]

Dick JE, Lapidot T, Pflumio F. Transplantation of normal and leukemic human bone marrow into immune-deficient mice: development of animal models for human hematopoiesis. Immunol Rev. 1991; 124:25-43. [PubMed: 1804779]

Eberl G. Inducible lymphoid tissues in the adult gut: recapitulation of a fetal developmental pathway? Nat Rev Immunol. 2005; 5:413-20. [PubMed: 15841100]

Eberl G. From induced to programmed lymphoid tissues: the long road to preempt pathogens. Trends Immunol. 2007; 28:423-8. [PubMed: 17826332]

Eberl G, Littman DR. Thymic origin of intestinal alphabeta T cells revealed by fate mapping of RORgammat+ cells. Science. 2004; 305:248-51. [PubMed: 15247480]

Guadalupe M, Reay E, Sankaran S, Prindiville T, Flamm J, McNeil A, Dandekar S. Severe CD4+ Tcell depletion in gut lymphoid tissue during primary human immunodeficiency virus type 1 infection and substantial delay in restoration following highly active antiretroviral therapy. $\mathrm{J}$ Virol. 2003; 77:11708-17. [PubMed: 14557656]

Hirsch HH, Kaufmann G, Sendi P, Battegay M. Immune reconstitution in HIV-infected patients. Clin Infect Dis. 2004; 38:1159-66. [PubMed: 15095223]

Hofer U, Baenziger S, Heikenwalder M, Schlaepfer E, Gehre N, Regenass S, Brunner T, Speck RF. RAG2-/- gamma(c)-/- mice transplanted with CD34+ cells from human cord blood show low levels of intestinal engraftment and are resistant to rectal transmission of human immunodeficiency virus. J Virol. 2008; 82:12145-53. [PubMed: 18842716]

Hogan C, Shpall E, McNulty O, McNiece I, Dick J, Shultz L, Keller G. Engraftment and development of human CD34(+)-enriched cells from umbilical cord blood in NOD/LtSz-scid/scid mice. Blood. 1997; 90:85-96. [PubMed: 9207442]

Holt N, Wang J, Kim K, Friedman G, Wang X, Taupin V, Crooks GM, Kohn DB, Gregory PD, Holmes MC, Cannon PM. Human hematopoietic stem/progenitor cells modified by zinc-finger 
nucleases targeted to CCR5 control HIV-1 in vivo. Nat Biotechnol. 2010; 28:839-47. [PubMed: 20601939]

Ishikawa F, Yasukawa M, Lyons B, Yoshida S, Miyamoto T, Yoshimoto G, Watanabe T, Akashi K, Shultz LD, Harada M. Development of functional human blood and immune systems in NOD/ SCID/IL2 receptor \{gamma\} chain(null) mice. Blood. 2005; 106:1565-73. [PubMed: 15920010]

Islas-Ohlmayer M, Padgett-Thomas A, Domiati-Saad R, Melkus MW, Cravens PD, del Martin MP, Netto G, Garcia JV. Experimental infection of NOD/SCID mice reconstituted with human CD34+ cells with Epstein-Barr virus. J Virol. 2004; 78:13891-900. [PubMed: 15564497]

Jung C, Hugot JP, Barreau F. Peyer's Patches: The Immune Sensors of the Intestine. Int J Inflam. 2010; 2010:823710. [PubMed: 21188221]

Kamel-Reid S, Dick JE. Engraftment of immune-deficient mice with human hematopoietic stem cells. Science. 1988; 242:1706-9. [PubMed: 2904703]

Kanamori Y, Ishimaru K, Nanno M, Maki K, Ikuta K, Nariuchi H, Ishikawa H. Identification of novel lymphoid tissues in murine intestinal mucosa where clusters of c-kit+ IL-7R+ Thy 1+ lymphohemopoietic progenitors develop. J Exp Med. 1996; 184:1449-59. [PubMed: 8879216]

Kiyono H, Fukuyama S. NALT- versus Peyer's-patch-mediated mucosal immunity. Nat Rev Immunol. 2004; 4:699-710. [PubMed: 15343369]

Kunkel EJ, Butcher EC. Chemokines and the tissue-specific migration of lymphocytes. Immunity. 2002; 16:1-4. [PubMed: 11825560]

Lan P, Tonomura N, Shimizu A, Wang S, Yang YG. Reconstitution of a functional human immune system in immunodeficient mice through combined human fetal thymus/liver and CD34+ cell transplantation. Blood. 2006; 108:487-92. [PubMed: 16410443]

Lugering A, Ross M, Sieker M, Heidemann J, Williams IR, Domschke W, Kucharzik T. CCR6 identifies lymphoid tissue inducer cells within cryptopatches. Clin Exp Immunol. 2010; 160:440 9. [PubMed: 20148914]

Macdonald TT, Monteleone G. Immunity, inflammation, and allergy in the gut. Science. 2005; 307:1920-5. [PubMed: 15790845]

Marodon G, Desjardins D, Mercey L, Baillou C, Parent P, Manuel M, Caux C, Bellier B, Pasqual N, Klatzmann D. High diversity of the immune repertoire in humanized NOD. SCID. gamma c-/mice. Eur J Immunol. 2009; 39:2136-45. [PubMed: 19572320]

Mebius RE. Organogenesis of lymphoid tissues. Nat Rev Immunol. 2003; 3:292-303. [PubMed: 12669020]

Mehandru S, Dandekar S. Role of the gastrointestinal tract in establishing infection in primates and humans. Curr Opin HIV AIDS. 2008; 3:22-7. [PubMed: 19372940]

Mehandru S, Poles MA, Tenner-Racz K, Jean-Pierre P, Manuelli V, Lopez P, Shet A, Low A, Mohri H, Boden D, Racz P, Markowitz M. Lack of Mucosal Immune Reconstitution during Prolonged Treatment of Acute and Early HIV-1 Infection. PLoS Med. 2006; 3:e484. [PubMed: 17147468]

Melkus MW, Estes JD, Padgett-Thomas A, Gatlin J, Denton PW, Othieno FA, Wege AK, Haase AT, Garcia JV. Humanized mice mount specific adaptive and innate immune responses to EBV and TSST-1. Nat Med. 2006; 12:1316-22. [PubMed: 17057712]

Moghaddami M, Cummins A, Mayrhofer G. Lymphocyte-filled villi: comparison with other lymphoid aggregations in the mucosa of the human small intestine. Gastroenterology. 1998; 115:1414-25. [PubMed: 9834269]

Mowat AM, Viney JL. The anatomical basis of intestinal immunity. Immunol Rev. 1997; 156:145-66. [PubMed: 9176706]

Nochi T, Denton PW, Wahl A, Garcia JV. Cryptopatches are essential for the development of human GALT. Cell Rep. 2013; 3:1874-84. [PubMed: 23791525]

Oida T, Suzuki K, Nanno M, Kanamori Y, Saito H, Kubota E, Kato S, Itoh M, Kaminogawa S, Ishikawa $\mathrm{H}$. Role of gut cryptopatches in early extrathymic maturation of intestinal intraepithelial T cells. J Immunol. 2000; 164:3616-26. [PubMed: 10725718]

Olesen R, Wahl A, Denton PW, Victor Garcia J. Immune reconstitution of the female reproductive tract of humanized BLT mice and their susceptibility to human immunodeficiency virus infection. J Reprod Immunol. 2011; 88:195-203. [PubMed: 21256601] 
Pabst O, Herbrand H, Worbs T, Friedrichsen M, Yan S, Hoffmann MW, Korner H, Bernhardt G, Pabst R, Forster R. Cryptopatches and isolated lymphoid follicles: dynamic lymphoid tissues dispensable for the generation of intraepithelial lymphocytes. Eur J Immunol. 2005; 35:98-107. [PubMed: 15580658]

Palucka AK, Gatlin J, Blanck JP, Melkus MW, Clayton S, Ueno H, Kraus ET, Cravens P, Bennett L, Padgett-Thomas A, Marches F, Islas-Ohlmayer M, Garcia JV, Banchereau J. Human dendritic cell subsets in NOD/SCID mice engrafted with CD34+ hematopoietic progenitors. Blood. 2003; 102:3302-10. [PubMed: 12869510]

Probert CS, Saubermann LJ, Balk S, Blumberg RS. Repertoire of the alpha beta T-cell receptor in the intestine. Immunol Rev. 2007; 215:215-25. [PubMed: 17291291]

Saito H, Kanamori Y, Takemori T, Nariuchi H, Kubota E, Takahashi-Iwanaga H, Iwanaga T, Ishikawa $\mathrm{H}$. Generation of intestinal T cells from progenitors residing in gut cryptopatches. Science. 1998; 280:275-8. [PubMed: 9535655]

Shacklett BL, Anton PA. HIV Infection and Gut Mucosal Immune Function: Updates on Pathogenesis with Implications for Management and Intervention. Curr Infect Dis Rep. 2010; 12:19-27. [PubMed: 20174448]

Shultz LD, Brehm MA, Garcia-Martinez JV, Greiner DL. Humanized mice for immune system investigation: progress, promise and challenges. Nat Rev Immunol. 2012; 12:786-98. [PubMed: 23059428]

Shultz LD, Lyons BL, Burzenski LM, Gott B, Chen X, Chaleff S, Kotb M, Gillies SD, King M, Mangada J, Greiner DL, Handgretinger R. Human lymphoid and myeloid cell development in NOD/LtSz-scid IL2R gamma null mice engrafted with mobilized human hemopoietic stem cells. J Immunol. 2005; 174:6477-89. [PubMed: 15879151]

Sun Z, Denton PW, Estes JD, Othieno FA, Wei BL, Wege AK, Melkus MW, Padgett-Thomas A, Zupancic M, Haase AT, Garcia JV. Intrarectal transmission, systemic infection, and CD4+ T cell depletion in humanized mice infected with HIV-1. J Exp Med. 2007; 204:705-14. [PubMed: 17389241]

Suzuki K, Oida T, Hamada H, Hitotsumatsu O, Watanabe M, Hibi T, Yamamoto H, Kubota E, Kaminogawa S, Ishikawa H. Gut cryptopatches: direct evidence of extrathymic anatomical sites for intestinal T lymphopoiesis. Immunity. 2000; 13:691-702. [PubMed: 11114381]

Traggiai E, Chicha L, Mazzucchelli L, Bronz L, Piffaretti JC, Lanzavecchia A, Manz MG. Development of a human adaptive immune system in cord blood cell-transplanted mice. Science. 2004; 304:104-7. [PubMed: 15064419]

van de Pavert SA, Mebius RE. New insights into the development of lymphoid tissues. Nat Rev Immunol. 2010; 10:664-74. [PubMed: 20706277]

Vormoor J, Lapidot T, Pflumio F, Risdon G, Patterson B, Broxmeyer H, Dick J. SCID mice as an in vivo model of human cord blood hematopoiesis. Blood Cells. 1994; 20:316-320. [PubMed: 7538337]

Wang JC, Lapidot T, Cashman JD, Doedens M, Addy L, Sutherland DR, Nayar R, Laraya P, Minden M, Keating A, Eaves AC, Eaves CJ, Dick JE. High level engraftment of NOD/SCID mice by primitive normal and leukemic hematopoietic cells from patients with chronic myeloid leukemia in chronic phase. Blood. 1998; 91:2406-14. [PubMed: 9516140]

Wang X, Rickert M, Garcia KC. Structure of the quaternary complex of interleukin-2 with its alpha, beta, and gammac receptors. Science. 2005; 310:1159-63. [PubMed: 16293754]

Wege AK, Melkus MW, Denton PW, Estes JD, Garcia JV. Functional and phenotypic characterization of the humanized BLT mouse model. Curr Top Microbiol Immunol. 2008; 324:149-65. [PubMed: 18481459] 


\section{Highlights}

- Gut associated lymphoid tissue is an important component of the immune system.

- Cryptopatches are essential for the development of GALT.

- Only certain strains of immunodeficient mice contain cryptopatches.

- Only strains of mice that have cryptopatches can develop human GALT. 